\title{
Tritrichomonas foetus infection, a cause of chronic diarrhea in the domestic cat
}

\author{
Chaoqun Yao ${ }^{1,3^{*}}$ and Liza S Köster ${ }^{2,3}$
}

\begin{abstract}
Tritrichomonas foetus is a very intriguing trichomonad protozoan with respect to its varied choice of residence in the different host species. It is an obligate parasite of the reproductive and the gastrointestinal tract of bovine and feline host respectively, leading to trichomonosis. Bovine trichomonosis is a sexually transmitted disease whereas feline trichomonosis is a disease with a purported fecal-oral route of spread. Further, the trichomonad is a commensal in the nasal passages, stomach, cecum and colon of swine host. Advances have been exponential in understanding the trichomonad biology and specifically feline trichomonosis since late 1990s and early 2000s when T. foetus was soundly determined to be a causative agent of chronic diarrhea in the domestic cat. It is a challenging task, even for a skilled investigator not to mention the busy clinical veterinarian, to keep up with the vast volume of information. Here we comprehensively reviewed the trichomonad biology, clinical manifestations, pathogenesis, host immunity, world map of distribution, risk factors, diagnosis and treatment. Risk factors associated with T. foetus-positive status in the domestic cat include young age, purebred, history of diarrhea, co-infections with other enteral pathogens. In addition, molecular similarity of bovine and feline isolates of $T$. foetus in DNA sequence was concisely discussed. The data presented serve as an information source for veterinarians, and investigators who are interested in biology of $T$. foetus and feline trichomonosis.
\end{abstract}

\section{Table of contents}

1. Introduction

2. Molecular studies

3. Survival of trophozoites in the environment and possible transmission route

4. Clinical signs associated with gastrointestinal tract infection

5. Infection in the urogenital tract

6. Pathogenesis

7. Host immunity

8. Epidemiology

8.1. Geographic distribution

8.2. Risk factors

8.2.1. Age

8.2.2. Breed

8.2.3. History of diarrhea

8.2.4. Co-infection with other enteric protozoa 8.2.5. Others

\footnotetext{
* Correspondence: chyao@rossvet.edu.kn

'Department of Biomedical Sciences, Ross University School of Veterinary Medicine, P.O. Box 334, Basseterre, St. Kitts, West Indies

${ }^{3}$ One Health Center for Zoonoses and Tropical Veterinary Medicine, Ross University School of Veterinary Medicine, P.O. Box 334, Basseterre, St. Kitts, West Indies

Full list of author information is available at the end of the article
}

9. Diagnosis

10. Treatment

11. Conclusions

12. List of abbreviations

13. Competing interests

14. Authors' contributions

15. Authors' information

16. Acknowledgments

17. References

\section{Introduction}

The genus Tritrichomonas belongs to the family Trichomonadidae. Among a few species of veterinary importance in the genus is Tritrichomonas foetus. Tritrichomonas foetus is fascinating both biologically and in its clinical manifestations in addition to being occasionally diagnosed in immunocompromised human beings [1]. It resides in the urogenital tract of cattle and causes bovine trichomonosis, a sexually transmitted disease with no approved treatment, throughout many geographic regions worldwide (bovine isolate) [2]. The same trichomonad species was soundly confirmed in 2003 to be the causative agent of chronic diarrhea in the domestic cat (feline isolate) [3,4] although the discovery of protozoan in these animals was made decades 
ago, as early as in 1928 [5]. Similar to other trichomonads such as human parasite Trichomonas vaginalis, T. foetus has only trophozoite stage although a pseudocyst stage is described [6-9]. Trophozoites reproduce asexually by longitudinal binary fission; no sexual reproduction has been ever discovered. They are pear- or spindle-shaped with three anterior flagella and one posterior flagellum. An undulating membrane extends along the whole length of the body and emerges as the posterior flagellum. The axostyle extends to the length of the cell and usually projects posteriorly. The size approximates $10-25 \mu \mathrm{m}$ in length and 3-15 $\mu \mathrm{m}$ in width (Figure 1).

Tritrichomonas foetus has been a topic of review, especially on the clinical aspects of feline trichomonosis [10-15]. The major purpose of the current manuscript is to comprehensively review trichomonad biology, geographic distributions with compiling a world map of distribution, risk factors, host immunity and pathogenesis of the feline isolate. Of course it would not be complete without briefly going over clinical signs, diagnosis, treatment and prognosis of feline trichomonosis.

\section{Molecular studies}

Feline isolates found in the gastrointestinal (GI) tract of the domestic cat and bovine isolates in the urogenital tract of cattle are morphologically indistinguishable. An identity of $100 \%$ has been found within each of both feline and bovine isolates among more than 5000 base pair (bp) at 11 loci by DNA sequencing [16-19]. Nevertheless, there are minor, but consistent differences among these loci, ranging from $0.3 \%$ of internal transcribed spacer (ITS) and cysteine protease (CP) 7 and 8 to $1.9 \%$ of CP6 gene [16-19] (see Table 1 for details of each locus). Lately, $0.7 \%$ difference were found among eight protease inhibitors covering a total of $4674 \mathrm{bp}$, with individual sequence length ranging from 297 to 1145 bp by a transcriptomical approach. Further, CP8 and CP7 were the most transcribed gene in bovine and feline isolate, respectively [20]. Based on the molecular sequence differences along with disparity of experimental crossinfections and divergence in pathogenicity Walden et al. proposed a new name for the feline isolate. They named it T. blagburni, a new trichomonad species [21]. However, these authors did not show a clear separation of feline from bovine isolate, a requirement for naming a new species. The new nomenclature, if holding up, still waits to be accepted, which may take a while, especially among veterinarians. Nevertheless, comparative transcriptomics revealed near identical functional category distribution of expressed genes with no indication of molecular level divergence, which strongly suggested feline and bovine isolates were taxonomically two isolates of one species [20]. It is not our intension, nor the scope of this manuscript deals with such a debate on taxonomical status of the pathogen causing chronic diarrhea in the domestic cat. Consequently, the name of $T$. foetus is kept in the current review as well as in the title referring the feline isolate unless otherwise stated in order to be consistent with literature and to avoid confusion among readers.

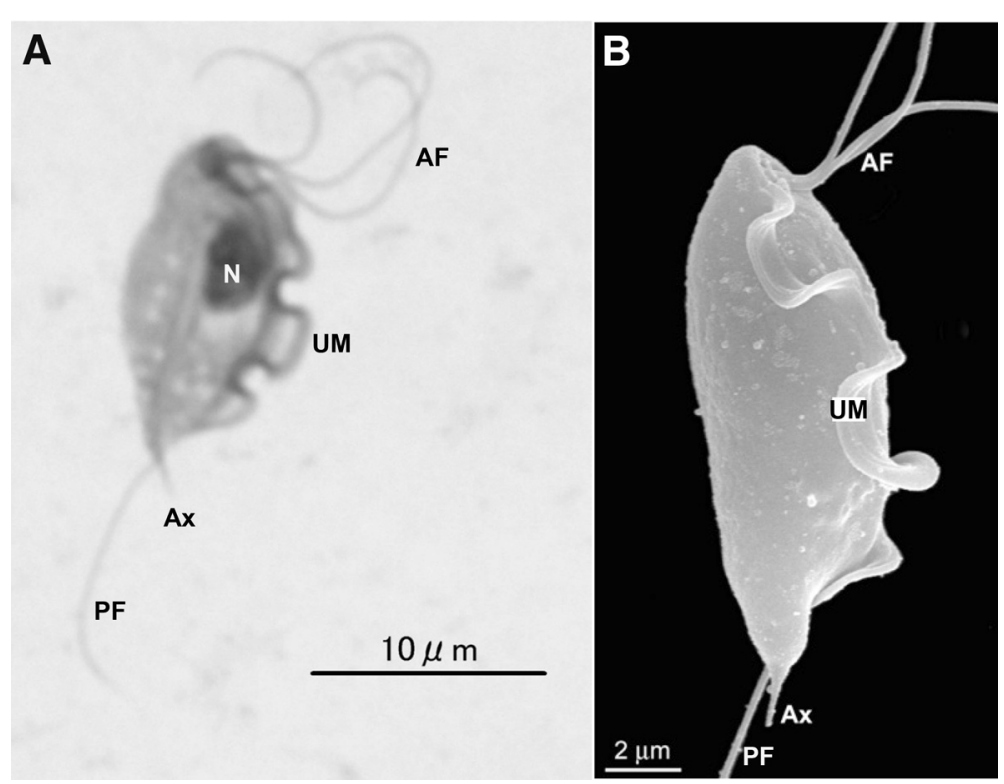

Figure 1 Tritrichomonas foetus trophozoites. A: Giemsa-stain. B: scanning electron microscopy. AF: anterior flagella; Ax: axostyle; N: nucleus; PF: posterior flagellum; UM: undulating membrane. A and B: reproduced from Figure 1 of Doi et al. ([80]) and Figure 1b of Midlej et al. [81], respectively, with permission. 
Table 1 Genetic similarity in percentage (\%) between feline isolates and bovine isolates of Tritrichomonas foetus

\begin{tabular}{|c|c|c|c|c|c|c|c|c|c|c|c|c|c|c|c|}
\hline \multirow[b]{2}{*}{ Feline isolates ${ }^{\#}$} & \multicolumn{14}{|c|}{ Bovine isolates* } & \multirow[t]{2}{*}{ Refs } \\
\hline & ITS (2) & ITS-2 (10) & EF-1a (10) & CP8 (2) & CP1 (8) & CP2 (8) & CP4 (8) & CP5 (8) & CP6 (8) & CP7 (8) & CP8 (8) & CP9 (8) & MDH1 (8) & ITS1 + $2(8)$ & \\
\hline ITS $(4,327)$ & 99.7 & & & & & & & & & & & & & & {$[17]$} \\
\hline ITS-2 $(4,368)$ & & 99.7 & & & & & & & & & & & & & {$[16]$} \\
\hline EF-1a $(4,783)$ & & & 99.4 & & & & & & & & & & & & {$[16]$} \\
\hline CP8 $(4,663)$ & & & & 99.7 & & & & & & & & & & & [19] \\
\hline CP1 $(7,503)$ & & & & & 99.4 & & & & & & & & & & [18] \\
\hline CP2 $(7,669)$ & & & & & & 96.7 & & & & & & & & & [18] \\
\hline CP4 $(7,273)$ & & & & & & & 99.3 & & & & & & & & [18] \\
\hline CP5 $(7,361)$ & & & & & & & & 99.2 & & & & & & & [18] \\
\hline CP6 $(7,318)$ & & & & & & & & & 98.1 & & & & & & [18] \\
\hline CP7 $(7,373)$ & & & & & & & & & & 99.7 & & & & & {$[18]$} \\
\hline CP8 $(7,907)$ & & & & & & & & & & & 99.4 & & & & {$[18]$} \\
\hline CP9 $(7,289)$ & & & & & & & & & & & & 99.3 & & & [18] \\
\hline $\mathrm{MDH} 1(7,562)$ & & & & & & & & & & & & & 99.6 & & {$[18]$} \\
\hline ITS1 + $2(7,297)$ & & & & & & & & & & & & & & 99.7 & [18] \\
\hline
\end{tabular}

$\mathrm{CP}$, cysteine protease; $\mathrm{MDH}$, malate dehydrogenase; ITS, internal transcribed spacer; EL, elongation factor. *number of cattle isolates.

"first number - number of cat isolates; second number - length of sequence in base pair (bp). 
In addition it is worth briefly describing another trichomonad, T. suis. The latter localizes at the nasal passages, stomach, cecum and colon of the domestic pig, and is morphologically indistinguishable from T. foetus. No differences have been found between $T$. suis and $T$. foetus bovine isolates at the molecular level such as random amplified polymorphic DNA (RAPD) [22-24], restriction fragment length polymorphism (RFLP) [24], and ITS-1 - 5.8S-rRNA - ITS-2 sequences $[25,26]$. Consequently they have been suggested synonyms, i.e. the same species [24,27]. Further sequence analysis of more than 5000 bp at 11 loci reveals $100 \%$ identity in all loci except elongation factor (EL)-1 $\alpha$ and CP8 with $99.4 \%$ and $99.7 \%$, respectively (Table 2). Together these molecular data confirm that T. suis and $T$. foetus bovine isolate are the same species, which makes $T$. foetus even more fascinating.

\section{Survival of trophozoites in the environment and possible transmission route}

Tritrichomonas foetus like many other trichomonad protozoa has only trophozoites stage. Under the experimental conditions four pathogen-free and four Cryptosporidium sp. infected cats were inoculated via orogastric intubation with $2 \times 10^{6}$ axenic T. foetus. All cats were persistently carrying the protozoan for the entire study period of over 200 days and experienced diarrhea that was self-resolved in seven weeks [28]. It is plausible that trophozoites are transmitted by a fecaloral route from an infected cat to an uninfected one. By doing so trophozoites have to overcome challenges they face and survive in: 1) the environment they encounter during the period between being discharged from one host and being ingested by the next; and 2) the hostile gastric niche of the new host after ingestion and before moving down to the intestine. A few studies have been done on these areas.

In an experiment that normally formed cat feces that were first mixed with saline in a 1:1 ratio, resulting in no form, loose, puddles or piles, were spiked with 10 -fold serially diluted trophozoites $\left(2 \times 10^{2}-2 \times 10^{5} /\right.$ gram feces) and stored at room temperature $\left(23-25{ }^{\circ} \mathrm{C}\right)$ for various length periods of time. An accumulative rate of more than $80 \%$ of positive culture for feces stored for 6 and $24 \mathrm{~h}$ was obtained in both InPouch ${ }^{\mathrm{tm}}$ and in Modified Diamond's Medium (MDM) [29]. It would be more relevant to find out how long the organisms would survive in diarrheic feces, which is currently unavailable. In another experiment cat food was spiked, the pathogens were cultivable for five consecutive days when MDM was used [30]. Similarly T. foetus trophozoites survived more than $3 \mathrm{~h}$ in feline urine and sauced cat food, $2 \mathrm{~h}$ on ground cat food although only half an hour in tap or distilled water [31]. These data collectively suggest that transmission is not solely limited to close contact between cats. Contamination of food and water by the trichomonads, although less likely in the latter, may be an important route for transmission. Further, garden slugs common in Sydney, Australia were fed cat foods spiked with $10^{6} \mathrm{~T}$. foetus feline isolate trophozoites per gram. One hundred percent and $83 \%$ of the Leopard slugs and the Yellow cellar slugs shed viable T. foetus in their feces, respectively, which was cultivable in MDM. Therefore slugs may facilitate the transmission of T. foetus among cats [30] as a vector. It is also plausible that these slugs may serve as transport hosts upon accidental ingestion by cats, which needs to be confirmed.

\section{Clinical signs associated with gastrointestinal tract infection}

Gastrointestinal disease has been demonstrated in cats experimentally infected with $T$. foetus, an organism not considered part of the normal feline microbiome $[3,28,32]$. It is possible to isolate $T$. foetus from a healthy cat as subclinical shedding does occur [33]. Infection can be demonstrated as early as 2 to 7 days after orogastric inoculation [28]. In experimental infection, $T$. foetus is limited to the ileum, cecum and colon [28]. Clinical signs vary from subclinical to intractable large bowel diarrhea [3]. Typical clinical signs in natural infections are chronic or intermittent large bowel diarrhea reported in about $61 \%$ to $64 \%$ of infected cats, with many cats having no reported diarrhea in the 6 months preceding diagnosis [34,35]. The feces has been described as yellow-green in color and malodorous with typical signs of colitis including fresh blood, mucous, fecal incontinence, tenesmus and flatulence $[3,36]$. The consistency of the feces has been described most commonly as semiformed to cow pat [28]. An objective fecal scoring system has been used in studies: a scale of 1 to 5 based on consistency, with a score of 1 representing watery feces and a score of 5 is dry and firm feces. Trichomonad infected cats fecal score have been described to range from 3 to 5 [33]. Up to as many as $20 \%$ of infected cats have reported systemic signs including anorexia, depression, vomiting and weight loss with a case report describing a kitten as pyrexic and experimental infections reporting vomiting and fever $[34,36,37]$. In a study examining experimental infection $(n=8)$, only two cats demonstrated clinical signs of disease, fecal blood and mucous at nine days post-infection (dpi), and fever with vomiting $21 \mathrm{dpi}$ [32]. Interestingly, motile trichomonads were observed in intestinal content culture in only three of the eight cats infected, none of which showed clinical signs. Mortality is extremely rare and only reported in kittens. The first report of mortality was in the study that first described natural and experimental trichomonosis in kittens in 1928 with a feline isolate [5]. All nine kittens 
Table 2 Genetic similarity in percentage (\%) between Tritrichomonas suis and bovine isolates of $T$. foetus

\begin{tabular}{|c|c|c|c|c|c|c|c|c|c|c|c|c|c|c|}
\hline \multirow[b]{2}{*}{ T. suis" } & \multicolumn{13}{|c|}{ Bovine isolates of $T$. foetus* } & \multirow[t]{2}{*}{ Refs. } \\
\hline & ITS-2 (10) & EF-1a (10) & CP8 (2) & CP1 (8) & CP2 (8) & CP4 (8) & CP5 (8) & CP6 (8) & CP7 (8) & CP8 (8) & CP9 (8) & MDH1 (8) & ITS1 + $2(8)$ & \\
\hline ITS-2 $(4,368)$ & 100.0 & & & & & & & & & & & & & [16] \\
\hline EF-1a $(4,783)$ & & 99.4 & & & & & & & & & & & & [16] \\
\hline CP8 $(4,663)$ & & & 99.7 & & & & & & & & & & & [19] \\
\hline CP1 $(4,503)$ & & & & 100.0 & & & & & & & & & & [18] \\
\hline CP2 $(4,669)$ & & & & & 100.0 & & & & & & & & & [18] \\
\hline CP4 $(4,273)$ & & & & & & 100.0 & & & & & & & & [18] \\
\hline CP5 $(4,361)$ & & & & & & & 100.0 & & & & & & & [18] \\
\hline CP6 $(4,318)$ & & & & & & & & 100.0 & & & & & & [18] \\
\hline CP7 $(4,373)$ & & & & & & & & & 100.0 & & & & & [18] \\
\hline CP8 $(4,907)$ & & & & & & & & & & $100.0(3) ; 99.9(1)$ & & & & [18] \\
\hline CP9 $(4,289)$ & & & & & & & & & & & 100.0 & & & [18] \\
\hline $\mathrm{MDH} 1(4,562)$ & & & & & & & & & & & & 100.0 & & [18] \\
\hline ITS1 + $2(4,297)$ & & & & & & & & & & & & & 100.0 & [18] \\
\hline
\end{tabular}

$\mathrm{P}$, cysteine protease; MDH, malate dehydrogenase; ITS, internal transcribed spacer.

*number of cattle isolates.

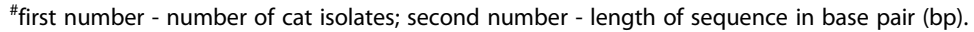


diagnosed with naturally acquired infection, and five of the six experimentally infected kittens, wasted and died within five to ten days and four to nine days of diagnosis respectively [5]. The second report that documents mortality was a prevalence study examining $T$. foetus infection in cats with diarrhea in a shelter colony in Italy [38]. One 7-month old kitten housed in this shelter with confirmed T. foetus infection succumbed to suspected septic shock despite having started ronidazole therapy two days prior [38].

Clinical signs are reported to persist for 5 to 24 months (median 9 months) from the time of diagnosis [33]. More than half of the cats that go into clinical remission will have PCR evidence of trichomonad infection (asymptomatic carrier), and many of these cats will relapse for a short duration, often with worse diarrhea [33]. Not surprisingly, the number of other cats in the same household will negatively impact the time from diagnosis to resolution of clinical signs [33]. Infection with $T$. foetus is not unlikely in single-cat households even in cats that have lived in isolation for years, as they can acquire the infection in the early stages of their lives [34]. Trichomonad infections can occur as co-infections, most notably Giardia species and coccidia [3,34,35,39]. More severe diarrhea has been reported in four cats experimentally infected with $T$. foetus and Cryptosporidium species, despite the latter organism having a tropism for the small intestines [28]. In surveys of naturally acquired trichomonad infections the severity of diarrhea has not reported to be worsened by co-infection with enteric parasites [35].

\section{Infection in the urogenital tract}

In addition to the GI tract T. foetus is also found in the urogenital tract of the domestic cat at least once. Dahlgren et al. reported the first case of $T$. foetus in the uterus of a cat with pyometra [40]. In this case wet mounts made directly from the fluid collected from the surgically removed uterus revealed microscopically numerous motile flagellated protozoa. They were $13-17 \times 5-7 \mu \mathrm{m}$ in size with undulating membrane, suggesting $T$. foetus. Further, PCR detected an expected size band product of $343 \mathrm{bp}$ in length using primers PRF3 and PRF4. The PCR product was sequenced and the sequence was $100 \%$ identical to T. foetus feline isolate sequences, which confirmed the identity of the protozoan causing feline pyometra as T. foetus [40]. T. foetus was also found in the feces of three other cats in the same household, one of which had chronic diarrhea [40]. These authors were unable to conclude that the infection was sexually transmitted even though the female mated repeatedly with $T$. foetus-positive male with chronic diarrhea [40].

In a comprehensive study Gray et al. used parallel samples collected in USA from both the urogenital tract as a result of ovariohysterectomy or castration and feces of purebred cats [41]. Direct microscopy, Immunohistochemical analysis and PCR were used to test each sample for the presence of $T$. foetus among the two sets of samples. Tritrichomonas foetus infections were detected by PCR in $25 \%(15 / 61)$ cats and $67 \%$ catteries $(22 / 33)$. Nevertheless, T. foetus was never detected in the urogenital tract of any cats, including the $15 \mathrm{~T}$. foetuspositive cats in feces. These authors concluded that no evidence of urogenital tract colonization by $T$. foetus was detected and that urogenital tract infection with $T$. foetus very unlikely plays an important role in overall disease transmission [41]. Collectively this data demonstrates that infection of the urogenital tract by $T$. foetus does occur and may cause pyometra, but it is a rare event especially among the healthy cats presenting to clinics for ovariohysterectomy or castration.

\section{Pathogenesis}

In the above mentioned experiment, four pathogen-free and four Cryptosporidium sp. infected cats were inoculated with axenic $T$. foetus. All cats experienced selfresolved diarrhea for weeks. Tritrichomonas foetus was isolated from the ileum, cecum, and colon during necropsy. It was further shown that protozoa and its surfacelocated antigen were detected on surface epithelia and within superficial detritus of the cecal and colonic mucosa (Figure 2) [28]. Similarly in naturally infected cats the parasites were generally present in close proximity to the mucosal surface and less frequently in the lumen of colonic crypts. Mild-to-moderate lymphoplasmacytic and neutrophilic colitis, crypt epithelial cell hypertrophy, hyperplasia and increased mitotic activity, loss of goblet cells were associated with the presence of trichomonads in colon [42]. Consequently in both experimental and natural infections the predilection sites for $T$. foetus trophozoites are the epithelial surface and crypts of cecum and colon.

Burgess et al. found that $T$. foetus bovine isolate was highly cytotoxic to Hela cells, a human cervical cell line, and early bovine lymphosarcoma (BL-3) but displayed low levels of cytotoxicity against Vero cells [43]. The latter are African green monkey kidney cells [43]. This isolate also adheres to bovine vaginal epithelial cells (BVECs) in an in vitro assay. The adhesion process was first initiated by the posterior flagellum followed by the body. $\operatorname{IgG}_{1}$ antibodies inhibited adherence, whereas $\mathrm{IgG}_{2}$ did not [44]. Furthermore, purified lipophosphoglycan (LPG) of $T$. foetus bovine isolate inhibited the binding of $T$. foetus to BVECs by competing with the protozoa in specific receptor - ligand interactions [45]. Adhesion of T. foetus resulted in extensive damage of BVEC monolayers [45]. This cytopathic effect was the results of apoptosis induced by T. foetus. A painstaking research pinpointed that CP8 of $30 \mathrm{kDa}$ was the major player in T. foetus inducing BVEC 


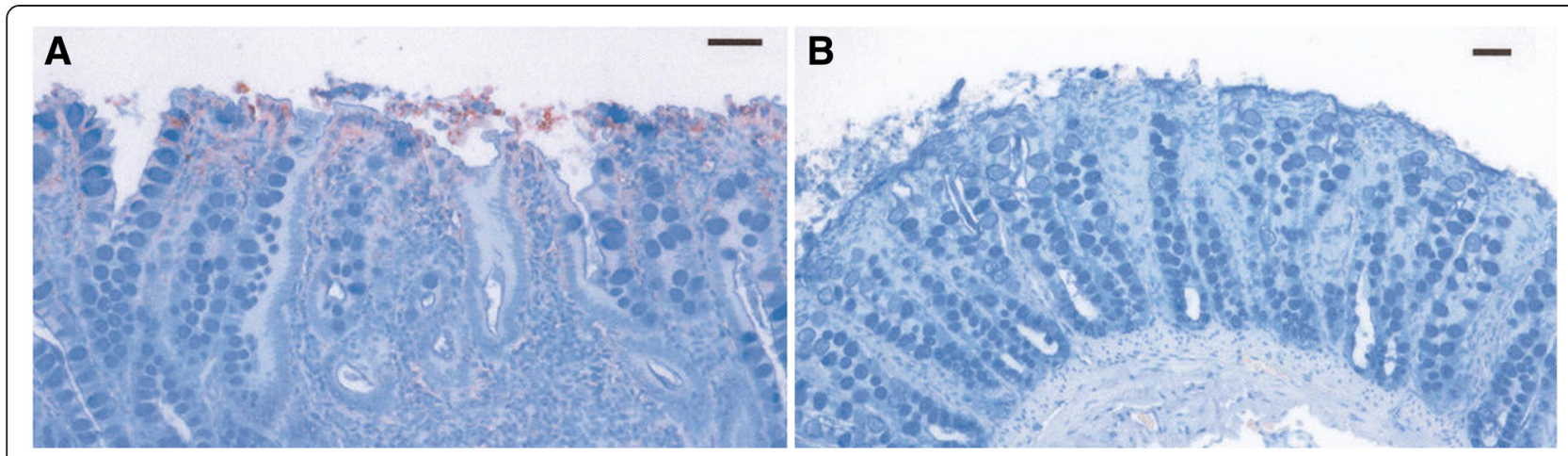

Figure 2 Tritrichomonas foetus antigens in colonic mucosal biopsy specimens. Immunolabeled trichomonads (red stained organisms) in panel $\mathbf{A}$ are located on surface enterocytes and within superficial mucus and detritus of the cecal mucosa. Panel $\mathbf{B}$ is a negative control omitting primary antibody. Bar $=100 \mu \mathrm{m}$. Reproduced with permission [28].

apoptosis [46]. Collectively the data from multiple research groups demonstrate that $T$. foetus bovine isolate causes cell death of BVECs by means of apoptosis, in which CPs such as CP8 plays a pivotal role. It is not clear whether the same occurs in vivo in infected cows and heifers, which waits to be confirmed.

In an in vitro analysis Tolbert et al. demonstrated that feline $T$. foetus trophozoites adhere to monolayers of the porcine intestinal epithelial cell line (IPEC)-J2 cells [47] (Figure 3). The reason for using a porcine jejunal cell line was the unavailability of epithelial cell line of feline origin. It is worthy of noting that $T$. suis, a synonym of $T$. foetus resides in the GI tract of pigs without causing clinical signs as mentioned in the section of molecular studies. So IPEC-J2 may represent the second best in vitro model. These authors showed that adhesion was via specific receptor - ligand interaction, required viable trichomonad cells and was independent of cytoskeletal activity of the trophozoites [47]. Lately the same authors elegantly demonstrated that feline $T$. foetus trophozoites progressively destroyed IPEC-J2 cell monolayer via apoptosis. The protozoan promoted a direct contact dependent activation of intestinal epithelial cell apoptosis signaling. This pathologic effect depended upon T. foetus cell associated cysteine proteases [48]. Effect of bovine $T$. foetus on epithelial cultured cells was investigated using clonal populations of the protozoan. Five clonal populations destroyed epithelial monolayers at different degrees, ranging from $25 \%$ to $55 \%$ despite similar cytoadhesion levels and whole-cell protease activity. They also showed various degrees of contact - dependent and contact independent cytotoxicity. Contact - independent cytotoxicity was strictly related to the degree of enzyme activation of an extracellular protease [49]. Furthermore, it was shown that extracellular proteinases such as CP8 of T. foetus bovine isolate cleaved C3b (the bigger fragment of two C3 component in the original paper designed as
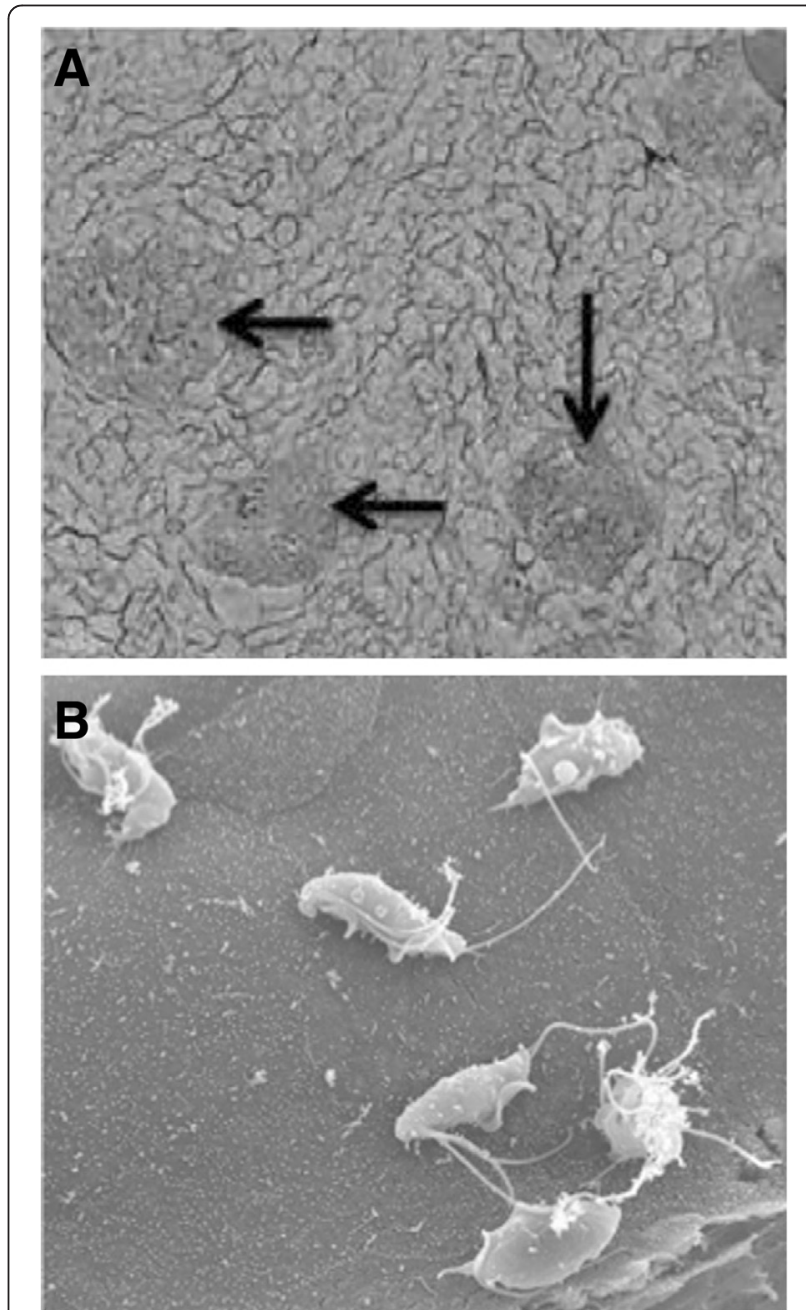

Figure 3 Scanning electron microscopy of Tritrichomonas foetus adhesion to porcine intestinal epithelial cell (IPEC)-J2 monolayers. A. Aggregates of trophozoites adhering to IPEC-J2 monolayers (arrows). B. Six trophoziotes adhering to a single IPEC-J2 cell. Reproduced with permission [47]. 
C3a) to small fragments, which could play a role in evasion of complement killing in vivo as a result of preventing completion of complement activation cascade [50].

Taken together, the pathogenesis of T. foetus on the intestinal epithelial cells is both contact - dependent and contact - independent. In the former, cytopathic effect is mainly via apoptosis induced by cell-associated proteases, whereas extracellular proteases are the major players in contact - independent cytotoxicity. Extracellular proteases may also play a role in evading complement killing. Consequently proteases are a major player although other uncharacterized molecules may also contribute to pathogenesis of this intriguing trichomonad. Consistent with the notion, 483 and 445 bovine and feline isolates of $T$. foetus transcripts were determined to be proteases by a transcriptomical approach. Among these 389 and 346 were CP, respectively [20].

\section{Host immunity}

There is significant paucity of literature on immunity of feline hosts to microbial infections in general and to T. foetus infections in the GI tract in specific. The latter is understandable provided that the trichomonad has been ascribed to be causative agents only in last 15 or so years. In general IgA is a pivotal player in mucosal secretion of cat's GI tract $[51,52]$. Consequently IgA profile in the GI tract among different age groups of various breeds is crucial to understand host immunity against and susceptibility to microbial infections. Unfortunately this information is very scarce at present. It was found very low concentrations of hyperimmune serum (up to 1:640 dilution, the highest available title in the experiments) promoted significant enhancement of killing of $T$. foetus bovine isolate by the alternative pathway of bovine complement [53]. Nevertheless, extracellular proteinases such as CP8 of $T$. foetus bovine isolate cleaved C3b to small inactive fragments, which may counteract this host defense system [50].

\section{Epidemiology}

\subsection{Geographic distribution}

Although T. foetus was reported in nine kittens with diarrhea as early as 1928 [5] its status as an etiological pathogen of chronic diarrhea of the domestic cat was only confirmed very recently. Gookin et al. established an association between diarrhea and $T$. foetus infections in the domestic cat in the USA [3]. They further determined that this trichomonad was the etiological agent of feline trichomonal diarrhea using rRNA gene sequence analysis; restriction enzyme digest mapping; and light, transmission, and scanning electron microscopy [4].

Tritrichomonas foetus has been diagnosed in the domestic cat in many geographic regions. To the best of our knowledge its geographic distribution has covered four continents including Europe (Austria, Finland, France, Germany, Greece, Italy, Netherland, Norway, Poland, Spain, Sweden, Switzerland, and UK), North America (Canada and USA), Australia/Oceania (Australia and New Zealand), and Asia (Japan and South Korea) (Figure 4). In some regions only case reports were available, whereas in others survey data were generated (Table 3). Many of the survey data were collected from diarrheic cats, show cat, cats in catteries, or cats presenting to veterinarians and veterinary clinics. Consequently there is a bias associated with such samples, i.e., a bias resulting in higher positive rate than cross-sectional samples that would have been collected from pet owners under the most scenarios. For instance in New Zealand, 22 samples of show cats revealed a positive rate of $82 \%$. In USA diarrheic cats had positive rate as low as $6 \%$ in one study [54], and as high as $40 \%$ in another [55]. Figure 4 shows the different geographic regions of the world where surveys have been conducted and/or cases have been reported.

\subsection{Risk factors}

Odds ratio (OR) is commonly used to quantitatively gauge risk factors. An OR is a measure of association between an exposure and an outcome [56]. In this section OR will be used either directly taken from the original publications or calculated by us if data allow to do so. Risk factors discussed in the section include age and breed of the animals, a history of diarrhea, co-infection with other enteral protozoa and housing conditions etc.

\subsubsection{Age}

An association between age of infected cats and T. foetus infections has been probed in many studies, of which several were showed in Table 4. A common notion is that cats of one year old or younger are more susceptible to T. foetus. However, data presented in Table 4 did not show a clear picture at all. OR for cats $\leq 1$ year old generated from data collected from France and UK were $2.5(P=$ $0.057)$ and 13.4 $(P<0.01)$, respectively [57,58]. Further, Galian et al. reported a positive association between age and T. foetus prevalence among 1391 fecal samples submitted to a diagnostic laboratory originated from 15 countries in the European Union [59]. They found 10.4\%, 5.5\%, $2.5 \%, 3.5 \%$ and $0 \% \mathrm{~T}$. foetus-positive cats among age groups $\leq 1$ year old, $2-7,8-11,12-15$ and $\geq 15$ years old, respectively [59]. However, data from Germany yielded a contradicted picture with younger cats marginally less susceptible with OR $0.9(P<0.05)$ [35]. Also no association was found from data collected from Canada, Norway, and USA [60-62] (Table 4). Collectively data from multiple countries do not consistently support a notion that $T$. foetus infections occur more often in the domestic cat of one year old or younger. 


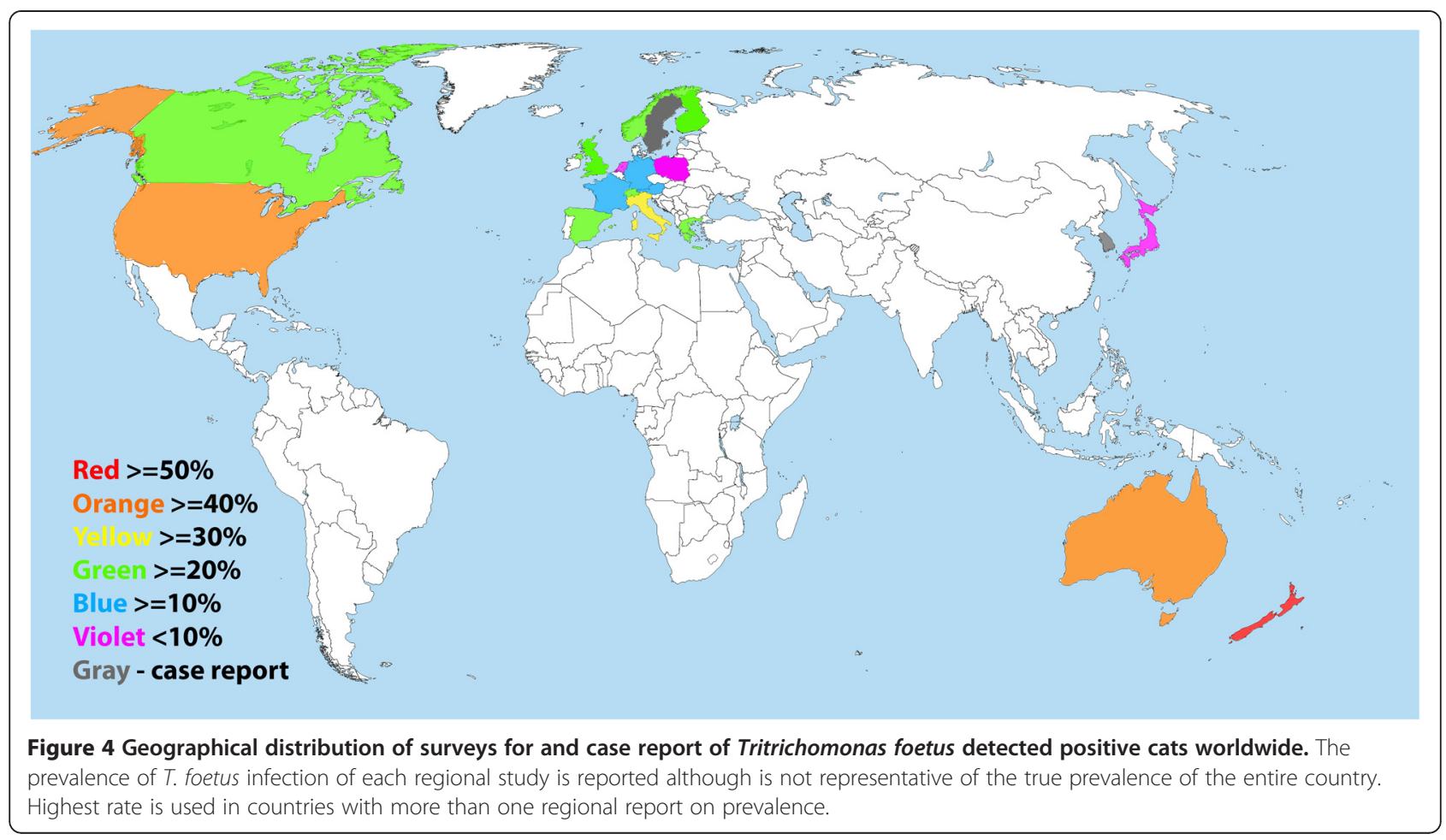

A metadata analysis on OR of cat of one year old or younger was performed by the current authors on available data in publications, which all happened to originate from various European countries (Table 5). The cats in this age group had an OR of 2.1 (1.7-2.6) than older animals. Therefore, young age is a risk factor for T. foetus infection.

\subsubsection{Breed}

There are many different pure breed and crossbreeds of the domestic cat throughout the world. Some breeds are more popular than the others in certain geographic regions. Many veterinarians have observed that purebreds present more often to clinics than crossbreds due to T. foetus infections. Among six sets of data all except one found this is true (Table 4). The only exception might be due to a small sample size. In this case, 20 T. foetus-positive samples were found in 140 show cats [58]. Purebreds have a much higher OR to be T. foetus positive than non-purebreds, which range from 26.3 in Canada [61] to >999.9 in UK [57]. Further analysis showed that a few breeds with a higher OR, such as 7.3 for Siamese and Bengal in UK [57], and 25.9 for Norwegian Forest in Germany [35]. Abyssinians, Siamese and Bengal were found more likely to be $T$. foetus positive in a survey carried out in USA [54]. Collectively purebred is a risk factor for T. foetus infections in general, and Abyssinians, Siamese, Bengal and Norwegian Forest in specific. Nevertheless, it is worthy of mentioning that some studies sampled purebred cats from cat breeding centers with a densely housed population. Under this scenario increased incidence of infection might be due to the reliance on close and direct contact among animals.

\subsubsection{History of diarrhea}

History of diarrhea can be the T. foetus positive cat itself, or the other cats sharing the same household in the past, say 6 months. In the former, two studies showed OR 3.2 $(P<0.05)$ in Germany [35] and $3.5(P<0.05)$ in USA [60]. Third study in Canada showed an OR 1.7 without statistical significance [61]. For the latter, two investigations resulted in ORs of 4.4 $(P<0.01)$ in Canada [61] and 3.2 in Germany $(P<0.01)$ [35]. Therefore, history of diarrhea in the past six months, no matter whether it is the presenting cat itself or its playmates, rendered a cat a threefold higher chance of having a $T$. foetuspositive status.

\subsubsection{Co-infection with other enteric protozoa}

Enteral protozoa of the domestic cat include, but are not limited to, T. foetus, Giardia duodenalis, Cryptosporidium spp. Toxoplasma gondii, Isospora spp. and Sarcocystis spp. Co-infection of these is not unusual. For example, five of 16T. foetus positive cats were Giardia sp. positive in Australia [63]; five of $18 \mathrm{~T}$. foetus positive cats were Giardia sp. positive in New Zealand [64]; ten, six and one of 36 T. foetus positive cats were Giardia sp., Isospora sp., and Cryptosporidium sp. positive, respectively, three were 
Table 3 Cases and prevalence of feline trichomonosis throughout the world

\begin{tabular}{|c|c|c|c|c|c|c|}
\hline Country & Year & Sources (cat examined) & Diagnosis & Case report & Prevalence (\%) & Refs \\
\hline Australia & & Vet Clinic & $M ; C ; P C R ; S$ & 16 & & {$[63]$} \\
\hline \multirow[t]{2}{*}{ Australia } & $2006-2010$ & Vet Clinic & $M: P C R$ & 13 & & {$[82]$} \\
\hline & 2008-2009 & Cattery (59) & PCR & & 42.4 & \\
\hline \multirow[t]{2}{*}{ Australia } & $2006-2007$ & Cattery (82) & $C ; P C R$ & & 0 & {$[83]$} \\
\hline & & Shelter (52) & & & 0 & \\
\hline Austria \& Germany & & Fecal samples (31) & $P C R, S$ & & 19.4 & {$[84]$} \\
\hline Austria & 1997-2008 & Necropsy (96); Organ samples (6) & $\begin{array}{l}\text { chromogenic in situ } \\
\text { hybridization; PCR; } S\end{array}$ & & 2.9 & {$[71]$} \\
\hline Canada & & Cats with chronical diarrhea (1) & PCR & 1 & & {$[85]$} \\
\hline \multirow[t]{3}{*}{ Canada } & $2011-2012$ & Cat Clinic (140) & C;PCR & & 0.7 & {$[61]$} \\
\hline & & Cat show (55) & & & 23.6 & \\
\hline & & Humane Society (46) & & & 0 & \\
\hline European Union - 15 countries & 2009-2010 & Diarrheic cats (1840) & $P C R, S$ & & 9.0 & {$[59,86]$} \\
\hline Finland & $2008-2010$ & Diagnostic samples (60) & PCR & & 28.3 & {$[87]$} \\
\hline France & $2009-2010$ & Cat show (140) & $C ; S$ & & 14.3 & {$[58]$} \\
\hline Germany & & Diarrheic cats (3) & $M, P C R, S$ & 3 & & {$[88]$} \\
\hline Germany & 2008 & Cat shows (230) & $C ; P C R ; S$ & & 15.7 & {$[35]$} \\
\hline Greece & & Fecal samples (30) & PCR & & 20.0 & {$[89]$} \\
\hline Italy & $2008-2010$ & $\begin{array}{l}\text { Pet (181), sheltered } \\
\text { cats (54), stray cats (28) }\end{array}$ & C & & 0 & [90] \\
\hline Italy & & Healthy pets (146) & PCR & & 2.1 & {$[65]$} \\
\hline Italy & 2006 & Rescued Cats (74) & $M ; C ; P C R$ & & 32.4 & {$[38]$} \\
\hline Japan & 2008 & Animal Hospitals (147) & $C ; P C R ; S$ & & 8.8 & {$[80]$} \\
\hline \multirow[t]{3}{*}{ Netherland } & 2006 & Diarrheic cats (53) & $P C R$ & & 2 & [91] \\
\hline & & Cattery (47) & & & 4 & \\
\hline & & pet (54) & & & 0 & \\
\hline New Zealand & 2006 & Cat shows (22) & $C ; P C R$ & & 81.8 & {$[64]$} \\
\hline Norway & 2006 & Vet Clinic & $M ; P C R ; S$ & 3 & & {$[40]$} \\
\hline Norway & 2009 & Cat show (52) & $C_{;} P C R ; S$ & & 21.2 & {$[62]$} \\
\hline Poland & & Vet Clinics (135) & $C ; P C R$ & & 7.3 & {$[92]$} \\
\hline South Korea & 2008 & Vet Clinic & $M ; C ; P C R$ & 2 & & {$[93]$} \\
\hline Spain & & Cattery (20) & $M ; C ; P C R$ & & 25.0 & {$[94]$} \\
\hline Sweden & & Diarrheic cats (1) & & 1 & & {$[95]$} \\
\hline Switzerland & 2007 & Diarrheic cats (45) & $C ; P C R ; S$ & & 24.4 & {$[96]$} \\
\hline Switzerland & $2007-2008$ & Vet Clinic (105) & $C ; P C R$ & & 25.7 & {$[97]$} \\
\hline UK & 2004 & Diarrheic cats (1) & $M ; P C R$ & 1 & & {$[36]$} \\
\hline UK & 2006 & Diarrheic cats (111) & $P C R$ & & 14.4 & {$[57]$} \\
\hline UK & $2010-2012$ & Diarrheic cats (1882) & PCR & & 18.8 & {$[66]$} \\
\hline UK & & Vet Clinic (163) & $P C R$ & & 20.0 & {$[98]$} \\
\hline USA & & Diarrheic cats (26) & $M ; C ; P C R$ & 26 & & {$[33]$} \\
\hline USA & & Diarrheic cats (32) & $M ; C$ & 32 & & {$[3]$} \\
\hline USA & & Diarrheic cats (1) & $M ; C ; P C R$ & 1 & & {$[75]$} \\
\hline USA & & Diarrheic cats (4) & $C ; P C R$ & 4 & & {$[74]$} \\
\hline USA & & Diarrheic cats (4) & $C ; P C R$ & 4 & & {$[78]$} \\
\hline USA & 2006-2009 & Vet Clinic (104) & PCR & 104 & & {$[34]$} \\
\hline
\end{tabular}


Table 3 Cases and prevalence of feline trichomonosis throughout the world (Continued)

\begin{tabular}{|c|c|c|c|c|c|c|}
\hline USA & & Diarrheic cat (7) & $M ; C ; P C R$ & 7 & & {$[42]$} \\
\hline \multirow[t]{2}{*}{ USA } & & nondiarrheic cats (53) & $C ; P C R$ & & 0.0 & [54] \\
\hline & & Diarrheic cats (170) & & & 5.9 & \\
\hline USA & & Fecal samples (173) & $C ; P C R$ & & 9.8 & [39] \\
\hline USA & & Catteries (61) & $\mathrm{M} ; \mathrm{PCR}$ & & 24.6 & [41] \\
\hline USA & 2001 & Cat show (117) & $M ; C ; P C R$ & & 30.8 & [60] \\
\hline USA & 2009-2012 & Diarrheic cats (68) & PCR & & 39.7 & [55] \\
\hline
\end{tabular}

C: Culture; M: Microscopy; PCR: polymerase chain reaction; S: Sequencing.

co-infected by all except Cryptosporidium sp. in a survey carried out in Germany [35]. In a survey of 146 fecal samples in Italy, co-infections were not found although 15, 11, 3 , and 3 were positive for T. gondii, G. duodenalis, Cryptosporidium sp. and T. foetus, respectively [65]. A detail analysis of enteropathogen co-infection in UK cats with diarrhea was carried out. There was greater co-occurrence than random of $G$. duodenalis with either $T$. foetus or Cryptosporidium sp. respectively. Further a greater threeway co-occurrence existed among these three enteral protozoa [66]. These data collectively show that these enteral protozoa render greater risk for the domestic cat to be infected with $T$. foetus even though they may locate at different niches than $T$. foetus.

\subsubsection{Others}

A few other factors have been analyzed for and found their association with T. foetus-positive status occasionally. One is sex. Among seven studies only one demonstrated being a male kitten is a great risk factor $(P<$ 0.01 ) [41]. Another one is housing with more than one other cat. One of four surveys showed sharing house with more than five cats had an OR $4.6(P<0.01)$ [61]. The third one is food, one of three investigations resulted in an OR 5.4 for feeding raw food diet $(P<0.01)$ [61]. What causes this disparity is beyond the scope of this manuscript. Plausible reasons include small sample sizes and confounding factors.

\section{Diagnosis}

Tritrichomonas foetus infection should be suspected in a cat with recent ( $<6$ months) clinical signs of chronic large bowel diarrhea, with highest risk in densely housed young, purebred, show cats $[3,60]$. There are no differences in the signalment between Giardia sp. and T. foetus infected cats and co-infections are common enough (12\%) to warrant testing for $T$. foetus despite the diagnosis of other enteric protozoal infection, although Giardia sp. is a small bowel parasite and the clinical signs should distinguish the infections. There have been no hematological or biochemical abnormalities reported in the literature. Diagnosis of a trichomonad infection is made by either the demonstration of the trophozoite on a saline diluted direct fecal smear (14.7\% sensitivity), culture by inoculating MDM (26.4\% sensitivity) or the commercially available InPouch ${ }^{\mathrm{TM}}$ TF medium (InPouch TF; BioMed Diagnostics, Inc, White City, OR USA) (58.8\% sensitivity) or the extraction of DNA in feces and the amplification of $T$. foetus rDNA by the use of PCR $[13,60]$. Fecal samples include either a voided stool or collected by manual extraction with the aid of fecal loops or by a colon flush technique. The technique of colon flush is demonstrated in a video clip the North Carolina (NC) State University, College of Veterinary Medicine (CVM) website (Colon Flush Technique [67]). Fecal wet preparation is viewed under $40 \times$ magnification. The motile characteristic of $T$. foetus differ from Giardia sp. in that it has a forward motility in contrast to a falling leaf motility of Giardia sp. as demonstrated in a video clip from the NC State University CVM website (T. foetus vs. Giardia [68]). Failing to distinguish the two trophozoites on microscopy, Giardia sp. can be confirmed by fecal enzyme-linked immunosorbent assay for Giardia-specific antigen [60]. In cases where T. foetus is suspected despite negative microscopy or fecal culture, when a faster turn-around time than culture is required, or for confirmation of an organism visible on microscopy, $T$. foetus cannot precisely be distinguished microscopically from Pentatrichomonas hominis, a commensal trichomonad, a commercially available PCR assay is available targeting part of the $18 \mathrm{~s}$ ribosomal RNA (rRNA). Submission of samples should be diarrheic and free from litter as formed stool rarely tests positive even if a subclinical shedder (NC State University CVM, Submission of Samples for T. foetus PCR Testing [69]). The sample, roughly the size of a lima bean should be submitted in a sterile tube and the remainder of the volume filled with isopropyl alcohol, without the need for refrigeration. Unfortunately PCR cannot prove the absence of infection.

Chronic experimentally induced infection with $T$. foetus is limited to the colon, cecum and ileum [28]. The distribution of $T$. foetus organisms within the colon is not homogenous and histopathological diagnosis on 
Table 4 Risk factors related to feline infections by Tritrichomonas foetus ${ }^{\text {" }}$

\begin{tabular}{|c|c|c|c|c|c|c|c|}
\hline Country & Age in month & Sex-male & Purebred & Housing & History of diarrhea in past 6 months & Food & Refs \\
\hline \multirow[t]{2}{*}{ Canada } & \multirow[t]{2}{*}{$<6-0.6(0.1-3.4)$} & \multirow[t]{2}{*}{$2.0(0.5-7.9)$} & \multirow[t]{2}{*}{$26.3(3.8-1142.2)^{* *}$} & \multirow{2}{*}{$\begin{array}{l}>5 \text { cats per house }- \\
4.6(1.3-20.8)^{* *}\end{array}$} & Another cat - $4.4(1.3-16.2)^{* *}$ & \multirow{2}{*}{$\begin{array}{l}\text { Fed a raw food } \\
\text { diet }-5.4(1.5-19.6)^{* *}\end{array}$} & \multirow[t]{2}{*}[61]{} \\
\hline & & & & & Self - $1.7(0.4-6.4)$ & & \\
\hline France & $<12-{ }^{\#} 2.5(0.6-10.2)^{+}$ & NC & NC & NC & & NC & [58] \\
\hline \multirow[t]{2}{*}{ Germany } & \multirow[t]{2}{*}{$\leq 12-0.9(0.7-1.0)^{*}$} & \multirow[t]{2}{*}{ NC } & \multirow[t]{2}{*}{ Norwegian Forest - $25.9(7.6-87.7)^{* * *}$} & \multirow[t]{2}{*}{ NC } & Another cat - $3.2(1.2-9.9)^{* *}$ & \multirow[t]{2}{*}{ NC } & \multirow[t]{2}{*}[35]{} \\
\hline & & & & & Self $-3.2(1.1-8.7)^{*}$ & & \\
\hline Norway & NC & NC & & NC & $N C(P=0.1)$ & & {$[62]$} \\
\hline \multirow[t]{2}{*}{ UK } & \multirow[t]{2}{*}{$6-12(29.4 \%)_{i}>12(15.2 \%)^{* * *}$} & & Pedigree (37.8\%); & & & & \multirow[t]{2}{*}[66]{} \\
\hline & & & Non-pedigree $(6.0 \%)^{* * *}$ & & & & \\
\hline \multirow[t]{2}{*}{ UK } & \multirow[t]{2}{*}{$\leq 12,{ }^{\#} 13.4(1.7-107.7)^{* *}$} & \multirow[t]{2}{*}{ NC } & \# > 999.9 & & & & \multirow[t]{2}{*}{ [57] } \\
\hline & & & Siamese and Bengal ${ }^{\#} 7.3(2.1-25.9)^{* *}$ & & & & \\
\hline USA & $\begin{array}{l}\text { Infected mean } 8 \text { vs } \\
\text { non- infected mean } 64.8^{* * *}\end{array}$ & & Abyssinians, Siamese and Bengal** & & & & [54] \\
\hline USA & & ${ }^{\#}>999.9^{* *}$ & & & & & [41] \\
\hline USA & NC & NC & & & Self $-3.5(1.1-11.3)^{*}$ & & {$[60]$} \\
\hline
\end{tabular}

"Odds ratio is given; $95 \%$ confidence interval is in bracket. Blank cells: no data available.

":Calculated by the authors of current manuscript according to [56]; $P$ value from the original paper.

${ }^{*} P<0.05$; ${ }^{*} P<0.01 ;{ }^{* * *} P<0.001 ;{ }^{+} P=0.057$.

NC: No correlation was detected. 
Table 5 Data included in metadata analysis of odds ratio of young cats with Tritrichonomas foetus infections

\begin{tabular}{|c|c|c|c|c|c|c|}
\hline \multicolumn{3}{|c|}{ One year old or younger } & \multicolumn{3}{|c|}{ Older than one year old } & \multirow[t]{2}{*}{ Reference } \\
\hline Positive & Negative & Total & Positive & Negative & Total & \\
\hline 13 & 35 & 48 & 1 & 36 & 37 & {$[57]$} \\
\hline 17 & 76 & 93 & 3 & 44 & 47 & {$[58]$} \\
\hline 65 & 563 & 628 & 33 & 730 & 763 & [59] \\
\hline 5 & 14 & 19 & 6 & 26 & 32 & {$[62]$} \\
\hline 100 & 313 & 413 & 92 & 515 & 607 & {$[66]$} \\
\hline 9 & 3 & 12 & 1 & 22 & 23 & {$[96]$} \\
\hline 209 & 1004 & 1213 & 136 & 1373 & 1509 & \\
\hline
\end{tabular}

samples procured by necropsy, surgery or endoscopy in cats with naturally acquired infection had a sensitivity of $56 \%$ [42]. The probability of diagnosing $T$. foetus infection on histopathology is increased with the number of samples submitted. Thus examination of multiple samples will increase the likelihood of diagnosis with a minimum of 6 colon samples required to have a $\geq 95 \%$ confidence of detecting $T$. foetus on at least one sample [42]. A species (sequence) specific fluorescent antibody in situ hybridization (FISH) probe has been developed for the detection of $T$. foetus on formalin fixed samples allowing confirmation of location and molecular identification of a trichomonad [70]. A study examined an chromogenic in situ hybridization (CISH) technique using $T$. foetus and $P$. hominis probes on formalin archived small and large intestinal samples collected from young ( 4 weeks to 2 years of age) cats with diarrhea [71]. This technique is apparently more reliable than FISH technique as mammalian red blood cells, roughly the same size as trichomonads, auto-fluoresce. Four of the 102 samples were found to be positive, with three testing positive for the $T$. foetus probe and one with the P. hominis probe.

\section{Treatment}

The natural course of diarrhea in cats infected with $T$. foetus is waxing and waning, giving the false impression that therapy may be effective, but often relapsing after discontinuation of treatment [3]. Trichomonads rely on hydrogenosomal fermentation of pyruvate making them susceptibility to 5-nitroimidazole antibiotics, such as metronidazole, tinidazole and ronidazole [72]. Therapeutics reported in the literature include: paromomycin, fenbendazole, furazolidone, nitazoxanide, metronidazole, tinidazole and ronidazole [3,28]. One of the earliest reported descriptions of treatment was paromomycin, an aminoglycoside used to treat Trichomonas vaginalis, a human protozoal infection of the genital tract, at the same dose used to treat cryptosporidiosis in cats [3]. In the 25 cats studied, evaluated 3 days to
6 months after treatment, only three had normal stool without $T$. foetus isolated from their stool. Forty percent of the cats in the study continued to have diarrhea after treatment, of which 9 had positive fecal smears, and in the 12 cats that had normal stools, $22 \%$ of those cats tested $(n=9)$ had positive fecal smears. Three of the cats in the study were kittens and 2 of them suffered sideeffects including acute renal failure, deafness and cataracts. These kittens were included in a case series of 4 kittens that suffered severe side-effects (acute renal failure, deafness and cataracts) after treatment with oral paromomycin [73]. Paromomycin has also been tested in vitro using a 24-h sensitivity assay and the results showed no effect at minimum lethal concentrations $($ MLC) $\leq 80 \mu \mathrm{g} / \mathrm{mL}$ [74]. Eleven of the original 25 cats were subsequently treated with fenbendazole and then 2 -weeks later by furazolidone [3]. There was a decrease in the number of cats having diarrhea, although the stool was described as semiformed in 9 of the cats with confirmed shedding trichomonads for the following 10-months. Furazolidone has shown equal 24-hour susceptibilities of $T$. foetus cultures to that of metronidazole and ronidazole at MLC of 0.625 to $2.5 \mu \mathrm{g} / \mathrm{mL}$ [74]. In experimentally infected cats, nitazoxanide, a nitrothiazole benzamide compound, with broad-spectrum antiprotozoal activity, decreased the number of trichomonads shed in the feces but failed to eliminate the $T$. foetus infection, although it did eliminate the cryptosporidial infection in those cats that were coinfected. Reported side-effects of nausea and foul-smelling dark diarrhea make it even less attractive as a therapeutic.

Nitroimidazoles (metronidazole, tinidazole and ronidazole) have been investigated both in vitro and in vivo in experimentally induced infections [74-76]. Metronidazole did not show any inhibitory effect in vitro at concentrations $\leq 10 \mu \mathrm{g} / \mathrm{mL}$ in contrast to tinidazole and ronidazole which had an inhibitory effect at MLC of $\geq 0.1 \mu \mathrm{g} / \mathrm{mL}$ [75]. Kather et al. demonstrated in vitro results that contradict these findings, as both metronidazole $(1.25$ to $2.5 \mu \mathrm{g} / \mathrm{mL}$ ) and ronidazole $(0.625$ to $2.5 \mu \mathrm{g} / \mathrm{mL}$ ) had a 24-h kill effect on T. foetus isolates, although ronidazole had lower 24-h MLC for some isolates [74]. Time-kill assays, which evaluate the degree of growth inhibition and survival during 24-h incubation demonstrated a significant difference in the survival kinetics of $T$. foetus in culture incubated with metronidazole as compared to ronidazole, with ronidazole being more effective [74]. Tinidazole has been investigated twice in vitro with reported MLC of $\geq 0.1 \mu \mathrm{g} / \mathrm{mL}$ and $\geq 10 \mu \mathrm{g} / \mathrm{mL}$ $[75,76]$. The disparity may be ascribable to different strains used in the two experiments.

The efficacy of metronidazole in vitro has not been translated to an in vivo efficacy, although transient improvement in clinical signs do occur independent of elimination of the $T$. foetus infection, the reasons proposed 
include alteration in bacterial microflora, elimination of Giardia co-infection or immunomodulatory effect [33,74]. Interestingly, treatment of infected cats with antibiotics that kill natural microbiota will increase shedding of T. foetus, as the organism is dependent on host bacteria for acquisition of micronutrients [75]. Tinidazole cleared experimentally induced $T$. foetus infection within 3-days, but the trichomonads were detected within 6 to 8 weeks after discontinuation of the treatment [76]. The poor in vivo efficacy may be related to its increased absorption and reduced concentration within the intestines. Ronidazole has been investigated in experimentally infected cats and shedding discontinued within 3-days of initiating therapy at $10 \mathrm{mg} / \mathrm{kg}$, dosed orally every $12 \mathrm{~h}$, although relapse was detected but the cultured organisms retrieved from the feces remained susceptible to ronidazole in vitro [75]. Relapses were reported in cats receiving a dose of $30 \mathrm{mg} / \mathrm{kg}$ twice daily but not in cats receiving $50 \mathrm{mg} / \mathrm{kg}$ twice daily. One reason for better efficacy of ronidazole as compared to other nitroimidazoles may be due to improved trapping of the activated compounds within the intestine [75].

Nitroimidazole resistant trichomonads are hydrogenosomal pyruvate:ferredoxin oxidoreductase deficient, and compensate by increased glycolysis and alternative cytosolic pathways. Ronidazole resistance is defined as aerobic MLC $\geq 100 \mu \mathrm{g} / \mathrm{mL}$ and is both inherent and acquired [77]. Resistant strains of T. foetus to ronidazole have been documented in cats with confirmed treatment failure after excluding the possibility of reinfection or urogenital nidus, and is related to the cross resistance of the organism to all nitroimidazole drugs [77].

Ronidazole is not registered for human or veterinary use and informed consent is necessary prior to use in cats and should only be prescribed in confirmed cases. The current recommended dose is $30 \mathrm{mg} / \mathrm{kg}$, once daily for 14-days [75]. Relapse is common and cats with resolved clinical signs can continue to carry the organism and thus vigilant and prolonged posttreatment monitoring is indicated. No adverse effects were reported in the original study that examined ronidazole as a treatment for $T$. foetus at doses as high as $50 \mathrm{mg} / \mathrm{kg}$, twice daily and hematology and biochemistry results remained within reference range and did not change as compared to pretreatment values [75]. Subsequent to this, four cases of neurological toxicity in cats treated with ronidazole in the range of 30 to $50 \mathrm{mg} / \mathrm{kg}$ were reported. The clinical signs included, having a blank stare, "slow motion" movements, agitation, facial tremors, trembling of the extremities, unable to jump or walk stairs and hyperesthesia which started three to nine days after initiating ronidazole, lasting one to four weeks in duration [78]. A lower dose of ronidazole, $10-30 \mathrm{mg} / \mathrm{kg}$ once daily, for 14 days, together with a probiotic (Pro-Kolin Enterogenic, Protexin, Probiotics International) was compared to a placebo control and ronidazole at the same dose, frequency and duration in age matched cats diagnosed with $T$. foetusassociated diarrhea [79]. No side-effects were noted with relapse reported in both groups but cats that received the probiotic with the ronidazole were less likely to relapse.

\section{Conclusions}

Feline trichomonosis is caused by $T$. foetus. The etiology was determined merely one and half a decades ago. The current manuscript comprehensively reviews the trichomonad biology and the disease itself. The authors hope this will provides individuals who are interesting in the topic with one source for updated information.

\section{Abbreviations}

bp: base pair; BL: bovine lymphosarcoma; BVEC: Bovine vaginal epithelial cells; CISH: Chromogenic in situ hybridization; CP: Cysteine protease; CVM: College of Veterinary Medicine; dpi: days post infection; EL: Elongation factor; FISH: Fluorescent antibody in situ hybridization; Gl: Gastrointestinal; IPEC: Porcine intestinal epithelial cell; ITS: Internal transcribed spacer; LPG: Lipophosphoglycan; MDH: malate dehydrogenase; MDM: Modified Diamond's Medium; MLC: Minimum lethal concentration; NC: North Carolina; OR: Odds ratio; RAPD: Random amplified polymorphic DNA; RFLP: Restriction fragment length polymorphism; RUSVM: Ross University School of Veterinary Medicine.

\section{Competing interests}

The authors declare that they have no competing interests.

\section{Authors' contributions}

CY conceived the manuscript, and wrote all sections except the ones by LSK who was responsible for clinical signs associated with gastrointestinal tract infection, diagnosis and treatment. Both authors read and approved the final manuscript.

\section{Authors' information}

CY is an Associate Professor of Parasitology at Ross University School of Veterinary Medicine (RUSVM). CY has studied T. foetus for more than five years and published five refereed paper on the subject and 45 refereed manuscripts on other topics. CY had headed the Parasitology section of Wyoming State Veterinary Laboratory (WSVL) between 2008 and 2013, where about 8000 T. foetus testing was annually performed. LSK is an European Specialist in Internal Medicine and an Assistant Professor of Internal Medicine at RUSVM. LSK has 15 years of clinical experience working with companion animals including cats as a veterinarian and has frequently diagnosed and treated feline trichomonosis.

\section{Acknowledgments}

The authors are very grateful to Dr A Lee Willingham of RUSVM for his critical review of the manuscript. Drs. Esteban Soto and Edyta Bajak of RUSVM translated literature published in Spanish and Polish, respectively. The cost for publication is provided by an intramural grant of RUSVM One Health Center for Zoonoses and Tropical Veterinary Medicine.

\section{Author details}

${ }^{1}$ Department of Biomedical Sciences, Ross University School of Veterinary Medicine, P.O. Box 334, Basseterre, St. Kitts, West Indies. ${ }^{2}$ Department of Clinical Sciences, Ross University School of Veterinary Medicine, P.O. Box 334, Basseterre, St. Kitts, West Indies. ${ }^{3}$ One Health Center for Zoonoses and Tropical Veterinary Medicine, Ross University School of Veterinary Medicine, P.O. Box 334, Basseterre, St. Kitts, West Indies. 
Received: 5 January 2015 Accepted: 4 March 2015

\section{Published online: 19 March 2015}

\section{References}

1. Yao C (2012) Opportunistic human infections caused by Tritrichomonas species: a mini-review. Clin Microbiol Newsl 34:127-131

2. Yao C (2013) Diagnosis of Tritrichomonas foetus-infected bulls, an ultimate approach to eradicate bovine trichomoniasis in US cattle? J Med Microbiol 62:1-9

3. Gookin JL, Breitschwerdt EB, Levy MG, Gager RB, Benrud JG (1999) Diarrhea associated with trichomonosis in cats. J Am Vet Med Assoc 215:1450-1454

4. Levy MG, Gookin JL, Poore M, Birkenheuer AJ, Dykstra MJ, Litaker RW (2003) Tritrichomonas foetus and not Pentatrichomonas hominis is the etiologic agent of feline trichomonal diarrhea. J Parasitol 89:99-104

5. Kessel JF (1928) Trichomoniasis in kittens. Trans R Soc Trop Med Hyg 22:61-80

6. Benchimol M (2004) Trichomonads under Microscopy. Microsc Microanal 10:528-550

7. Lipman NS, Lampen N, Nguyen HT (1999) Identification of pseudocysts of Tritrichomonas muris in Armenian hamsters and their transmission to mice. Lab Anim Sci 49:313-315

8. Mariante RM, Lopes LC, Benchimol M (2004) Tritrichomonas foetus pseudocysts adhere to vaginal epithelial cells in a contact-dependent manner. Parasitol Res 92:303-312

9. Pereira-Neves A, Ribeiro KC, Benchimol M (2003) Pseudocysts in trichomonads-new insights. Protist 154:313-329

10. Gruffydd-Jones T, Addie D, Belak S, Boucraut-Baralon C, Egberink H, Frymus T, Hartmann K, Hosie MJ, Lloret A, Lutz H, Marsilio F, Möstl K, Pennisi MG, Radford AD, Thiry E, Truyen U, Horzinek MC (2013) Tritrichomoniasis in cats: $A B C D$ guidelines on prevention and management. J Feline Med Surg 15:647-649

11. Lappin MR (2005) Enteric protozoal diseases. Vet Clin North Am Small Anim Pract 35:81-88

12. Levy MG, Gookin JL, Poore MF, Litaker RW, Dykstra M (2001) Information on parasitic gastrointestinal tract infections in cats. J Am Vet Med Assoc 218:194-195

13. Manning K (2010) Update on the diagnosis and management of Tritrichomonas foetus infections in cats. Top Companion Anim Med 25:145-148

14. Payne PA, Artzer M (2009) The biology and control of Giardia spp and Tritrichomonas foetus. Vet Clin North Am Small Anim Pract 39:993-1007

15. Tolbert MK, Gookin J (2009) Tritrichomonas foetus: a new agent of feline diarrhea. Compend Contin Educ Vet 31:374-381

16. Reinmann K, Muller N, Kuhnert P, Campero CM, Leitsch D, Hess M, Henning K, Fort M, Muller J, Gottstein B, Frey CF (2012) Tritrichomonas foetus isolates from cats and cattle show minor genetic differences in unrelated loci ITS-2 and EF-1alpha. Vet Parasitol 185:138-144

17. Slapeta J, Craig S, McDonell D, Emery D (2010) Tritrichomonas foetus from domestic cats and cattle are genetically distinct. Exp Parasitol 126:209-213

18. Slapeta J, Muller N, Stack CM, Walker G, Lew-Tabor A, Tachezy J, Frey CF (2012) Comparative analysis of Tritrichomonas foetus (Riedmuller, 1928) cat genotype, T. foetus (Riedmuller, 1928) cattle genotype and Tritrichomonas suis (Davaine, 1875) at 10 DNA loci. Int J Parasitol 42:1143-1149

19. Sun Z, Stack C, Slapeta J (2012) Sequence differences in the diagnostic region of the cysteine protease 8 gene of Tritrichomonas foetus parasites of cats and cattle. Vet Parasitol 186:445-449

20. Morin-Adeline V, Lomas R, O'Meally D, Stack C, Conesa A, Sapeta J (2014) Comparative transcriptomics reveals striking similarities between the bovine and feline isolates of Tritrichomonas foetus: consequences for in silico drug-target identification. BMC Genomics 15:955

21. Walden HS, Dykstra C, Dillon A, Rodning S, Givens D, Bird R, Newton J, Lindsay D (2013) A new species of Tritrichomonas (Sarcomastigophora: Trichomonida) from the domestic cat (Felis catus). Parasitol Res 112:2227-2235

22. Felleisen RS (1998) Comparative genetic analysis of tritrichomonadid protozoa by the random amplified polymorphic DNA technique. Parasitol Res 84:153-156

23. Hampl V, Pavlicek A, Flegr J (2001) Construction and bootstrap analysis of DNA fingerprinting-based phylogenetic trees with the freeware program FreeTree: application to trichomonad parasites. Int J Syst Evol Microbiol 51:731-735

24. Tachezy J, Tachezy R, Hampl V, Sedinova M, Vanacova S, Vrlik M, Van Ranst M, Flegr J, Kuldaa J (2002) Cattle pathogen Tritrichomonas foetus (Riedmuller, 1928) and pig commensal Tritrichomonas suis (Gruby \& Delafond, 1843) belong to the same species. J Eukaryot Microbiol 49:154-163
25. Kleina P, Bettim-Bandinelli J, Bonatto SL, Benchimol M, Bogo MR (2004) Molecular phylogeny of Trichomonadidae family inferred from ITS-1, 5.8S rRNA and ITS-2 sequences. Int J Parasitol 34:963-970

26. Walker RL, Hayes DC, Sawyer SJ, Nordhausen RW, Van Hoosear KA, BonDurant RH (2003) Comparison of the 5.8S rRNA gene and internal transcribed spacer regions of trichomonadid protozoa recovered from the bovine preputial cavity. J Vet Diagn Invest 15:14-20

27. Lun ZR, Chen XG, Zhu XQ, Li XR, Xie MQ (2005) Are Tritrichomonas foetus and Tritrichomonas suis synonyms? Trends Parasitol 21:122-125

28. Gookin JL, Levy MG, Law JM, Papich MG, Poore MF, Breitschwerdt EB (2001) Experimental infection of cats with Tritrichomonas foetus. Am J Vet Res 62:1690-1697

29. Hale S, Norris JM, Slapeta J (2009) Prolonged resilience of Tritrichomonas foetus in cat faeces at ambient temperature. Vet Parasitol 166:60-65

30. Van der Saag M, McDonell D, Slapeta J (2011) Cat genotype Tritrichomonas foetus survives passage through the alimentary tract of two common slug species. Vet Parasitol 177:262-266

31. Rosypal AC, Ripley A, Stockdale Walden HD, Blagburn BL, Grant DC, Lindsay DS (2012) Survival of a feline isolate of Tritrichomonas foetus in water, cat urine, cat food and cat litter. Vet Parasitol 185:279-281

32. Stockdale HD, Dillon AR, Newton JC, Bird RC, Bondurant RH, Deinnocentes P, Barney S, Bulter J, Land T, Spencer JA, Lindsay DS, Blagburn BL (2008) Experimental infection of cats (Felis catus) with Tritrichomonas foetus isolated from cattle. Vet Parasitol 154:156-161

33. Foster DM, Gookin JL, Poore MF, Stebbins ME, Levy MG (2004) Outcome of cats with diarrhea and Tritrichomonas foetus infection. J Am Vet Med Assoc 225:888-892

34. Xenoulis PG, Lopinski DJ, Read SA, Suchodolski JS, Steiner JM (2013) Intestinal Tritrichomonas foetus infection in cats: a retrospective study of 104 cases. J Feline Med Surg 15:1098-1103

35. Kuehner KA, Marks SL, Kass PH, Sauter-Louis C, Grahn RA, Barutzki D, Hartmann K (2011) Tritrichomonas foetus infection in purebred cats in Germany: prevalence of clinical signs and the role of co-infection with other enteroparasites. J Feline Med Surg 13:251-258

36. Mardell EJ, Sparkes AH (2006) Chronic diarrhoea associated with Tritrichomonas foetus infection in a British cat. Vet Rec 158:765-766

37. Stockdale H, Rodning S, Givens M, Carpenter D, Lenz S, Spencer J, Dykstra C, Lindsay D, Blagburn B (2007) Experimental infection of cattle with a feline isolate of Tritrichomonas foetus. J Parasitol 93:1429-1434

38. Holliday M, Deni D, Gunn-Moore DA (2009) Tritrichomonas foetus infection in cats with diarrhoea in a rescue colony in Italy. J Feline Med Surg 11:131-134

39. Stockdale HD, Givens MD, Dykstra CC, Blagburn BL (2009) Tritrichomonas foetus infections in surveyed pet cats. Vet Parasitol 160:13-17

40. Dahlgren SS, Gjerde B, Pettersen HY (2007) First record of natural Tritrichomonas foetus infection of the feline uterus. J Small Anim Pract 48:654-657

41. Gray SG, Hunter SA, Stone MR, Gookin JL (2010) Assessment of reproductive tract disease in cats at risk for Tritrichomonas foetus infection. Am J Vet Res 71:76-81

42. Yaeger MJ, Gookin JL (2005) Histologic features associated with tritrichomonas foetus-induced colitis in domestic cats. Vet Pathol 42:797-804

43. Burgess DE, Knoblock KF, Daugherty T, Robertson NP (1990) Cytotoxic and hemolytic effects of Tritrichomonas foetus on mammalian cells. Infect Immun 58:3627-3632

44. Corbeil LB, Hodgson JL, Jones DW, Corbeil RR, Widders PR, Stephens LR (1989) Adherence of Tritrichomonas foetus to bovine vaginal epithelial cells. Infect Immun 57:2158-2165

45. Singh BN, Lucas JJ, Beach DH, Shin ST, Gilbert RO (1999) Adhesion of Tritrichomonas foetus to bovine vaginal epithelial cells. Infect Immun 67:3847-3854

46. Singh BN, Lucas JJ, Hayes GR, Kumar I, Beach DH, Frajblat M, Gilbert RO, Sommer U, Costello CE (2004) Tritrichomonas foetus induces apoptotic cell death in bovine vaginal epithelial cells. Infect Immun 72:4151-4158

47. Tolbert MK, Stauffer SH, Gookin JL (2013) Feline Tritrichomonas foetus adhere to intestinal epithelium by receptor-ligand-dependent mechanisms. Vet Parasitol 192:75-82

48. Tolbert MK, Stauffer SH, Brand MD, Gookin JL (2014) Cysteine protease activity of feline Tritrichomonas foetus promotes adhesion-dependent cytotoxicity to intestinal epithelial cells. Infect Immun 82:2851-2859

49. Da Rocha-Azevedo B, De Melo-Braga MB, Silva-Filho FC E (2005) Intra-strain clonal phenotypic variation of Tritrichomonas foetus is related to the cytotoxicity exerted by the parasite to cultured cells. Parasitol Res 95:106-112 
50. Kania SA, Reed SL, Thomford JW, BonDurant RH, Hirata K, Corbeil RR, North MJ, Corbeil LB (2001) Degradation of bovine complement C3 by trichomonad extracellular proteinase. Vet Immunol Immunopathol 78:83-96

51. Allenspach K (2011) Clinical immunology and immunopathology of the canine and feline intestine. Vet Clin North Am Small Anim Pract 41:345-360

52. Stokes C, Waly N (2006) Mucosal defence along the gastrointestinal tract of cats and dogs. Vet Res 37:281-293

53. Aydintug MK, Leid RW, Widders PR (1990) Antibody enhances killing of Tritrichomonas foetus by the alternative bovine complement pathway. Infect Immun 58:944-948

54. Queen EV, Marks SL, Farver TB (2012) Prevalence of selected bacterial and parasitic agents in feces from diarrheic and healthy control cats from Northern California. J Vet Intern Med 26:54-60

55. Polak KC, Levy JK, Crawford PC, Leutenegger CM, Moriello KA (2014) Infectious diseases in large-scale cat hoarding investigations. Vet J 201:189-195

56. Szumilas M (2010) Explaining Odds Ratios. J Can Acad Child Adolesc Psychiatry 19:227-229

57. Gunn-Moore DA, McCann TM, Reed N, Simpson KE, Tennant B (2007) Prevalence of Tritrichomonas foetus infection in cats with diarrhoea in the UK. J Feline Med Surg 9:214-218

58. Profizi C, Cian A, Meloni D, Hugonnard M, Lambert V, Groud K, Gagnon AC, Viscogliosi E, Zenner $L$ (2013) Prevalence of Tritrichomonas foetus infections in French catteries. Vet Parasitol 196:50-55

59. Galián M, Heusinger A, Gentil M, Müller E (2011) Tritrichomonas fetus in cats. Argos - Informativo Veterinario 134:44-45.

60. Gookin JL, Stebbins ME, Hunt E, Burlone K, Fulton M, Hochel R, Talaat M, Poore M, Levy MG (2004) Prevalence of and risk factors for feline Tritrichomonas foetus and giardia infection. J Clin Microbiol 42:2707-2710

61. Hosein A, Kruth SA, Pearl DL, Richardson D, Maggs JC, Peach HA, Peregrine AS (2013) Isolation of Tritrichomonas foetus from cats sampled at a cat clinic, cat shows and a humane society in southern Ontario. J Feline Med Surg 15:706-711

62. Tysnes K, Gjerde B, Nodtvedt A, Skancke E (2011) A cross-sectional study of Tritrichomonas foetus infection among healthy cats at shows in Norway. Acta Vet Scand 53:39

63. Bissett SA, Gowan RA, O'Brien CR, Stone MR, Gookin JL (2008) Feline diarrhoea associated with Tritrichomonas cf. foetus and Giardia co-infection in an Australian cattery. Aust Vet J 86:440-443

64. Kingsbury DD, Marks SL, Cave NJ, Grahn RA (2010) Identification of Tritrichomonas foetus and Giardia spp. infection in pedigree show cats in New Zealand. N Z Vet J 58:6-10

65. Mancianti F, Nardoni S, Mugnaini L, Zambernardi L, Guerrini A, Gazzola V, Papini RA (2015) A retrospective molecular study of select intestinal protozoa in healthy pet cats from Italy. J Feline Med Surg 17:163-167

66. Paris J, Wills S, Balzer H-J, Shaw D, Gunn-Moore D (2014) Enteropathogen co-infection in UK cats with diarrhoea. BMC Vet Res 10:13

67. Colon Flush Technique [http://www.youtube.com/watch?v=JMfZ9M80V8E] Accessed 15 Jan 2015

68. T. foetus vs. Giardia [http://www.youtube.com/watch?v=aF06jlbcF8E] Accessed 15 Jan 2015

69. NC State University CVM, Submission of Samples for T. foetus PCR Testing [http://www.JodyGookin.com]. Accessed 15 Jan 2015

70. Gookin JL, Stone MR, Yaeger MJ, Meyerholz DK, Moisan P (2010) Fluorescence in situ hybridization for identification of Tritrichomonas foetus in formalin-fixed and paraffin-embedded histological specimens of intestinal trichomoniasis. Vet Parasitol 172:139-143

71. Mostegl MM, Wetscher A, Richter B, Nedorost N, Dinhopl N, Weissenbock H (2012) Detection of Tritrichomonas foetus and Pentatrichomonas hominis in intestinal tissue specimens of cats by chromogenic in situ hybridization. Vet Parasitol 183:209-214

72. Kulda J (1999) Trichomonads, hydrogenosomes and drug resistance. Int J Parasitol 29:199-212

73. Gookin JL, Riviere JE, Gilger BC, Papich MG (1999) Acute renal failure in four cats treated with paromomycin. J Am Vet Med Assoc 215:1821-1823. 1806

74. Kather EJ, Marks SL, Kass PH (2007) Determination of the in vitro susceptibility of feline Tritrichomonas foetus to 5 antimicrobial agents. J Vet Intern Med 21:966-970

75. Gookin JL, Copple CN, Papich MG, Poore MF, Stauffer SH, Birkenheuer AJ, Twedt DC, Levy MG (2006) Efficacy of ronidazole for treatment of feline Tritrichomonas foetus infection. J Vet Intern Med 20:536-543
76. Gookin JL, Stauffer SH, Coccaro MR, Poore MF, Levy MG, Papich MG (2007) Efficacy of tinidazole for treatment of cats experimentally infected with Tritrichomonas foetus. Am J Vet Res 68:1085-1088

77. Gookin JL, Stauffer SH, Dybas D, Cannon DH (2010) Documentation of in vivo and in vitro aerobic resistance of feline Tritrichomonas foetus isolates to ronidazole. J Vet Intern Med 24:1003-1007

78. Rosado TW, Specht A, Marks SL (2007) Neurotoxicosis in 4 cats receiving ronidazole. J Vet Intern Med 21:328-331

79. Lalor SL, Gunn-Moore DA (2012) Effects of concurrent ronidazole and probiotic therapy in cats with Tritrichomonas foetus-associated diarrhoea. J Feline Med Surg 14:650-658

80. Doi J, Hirota J, Morita A, Fukushima K, Kamijyo H, Ohta H, Yamasaki M, Takahashi T, Katakura K, Oku Y (2012) Intestinal Tritrichomonas suis (=T. foetus) infection in Japanese cats. J Vet Med Sci 74:413-417

81. Midlej V, Pereira-Neves A, Kist LW, Bogo MR, Benchimol M (2011) Ultrastructural features of Tritrichomonas mobilensis and comparison with Tritrichomonas foetus. Vet Parasitol 182:171-180

82. Bell ET, Gowan RA, Lingard AE, McCoy RJ, Slapeta J, Malik R (2010) Naturally occurring Tritrichomonas foetus infections in Australian cats: 38 cases. J Feline Med Surg 12:889-898

83. Bissett SA, Stone ML, Malik R, Norris JM, O'Brien C, Mansfield CS, Nicholls JM, Griffin A, Gookin JL (2009) Observed occurrence of Tritrichomonas foetus and other enteric parasites in Australian cattery and shelter cats. J Feline Med Surg 11:803-807

84. Steiner JM, Xenoulis PG, Read SA, Suchodolski JS, Globokar M, Huisinga E, Thuere S (2007) Identification of Tritrichomonas foetus DNA in feces from cats with diarrhea from Germany and Austria. J Vet Intern Med 21:649

85. Pham D (2009) Chronic intermittent diarrhea in a 14-month-old Abyssinian cat. Can Vet J 50:85-87

86. Galián M, Gentil M, Heusinger A, Müller E (2011) Tritrichomonas foetus as a cause of diarrhoea in cats. Tierärztliche Umschau Parasiten-Spezial 1:5-8

87. Castrén L, Vainio-Siukola K, Laaksonen I, Saari S (2011) Tritrichomonas foetus as a cause of feline chronic large bowel diarrhoea. Suomen Eläinlääkärilehti 117:371-378

88. Schrey C, Mundhenk L, Grubers A, Henning K, Frey C (2009) Tritrichomonas foetus as a cause of diarrhoea in three cats. Kleintierpraxis 54:93-96

89. Xenoulis PG, Saridomichelakis MN, Read SA, Suchodolski JS, Steiner JM (2010) Detection of Tritrichomonas foetus in cats in Greece. J Feline Med Surg 12:831-833

90. Mugnaini L, Papini R, Gorini G, Passantino A, Merildi V, Mancianti F (2012) Pattern and predictive factors of endoparasitism in cats in Central Italy. Rev Med Vet 163:89-94

91. van Doorn DC, de Bruin MJ, Jorritsma RA, Ploeger HW, Schoormans A (2009) Prevalence of Tritrichomonas foetus among Dutch cats. Tijdschr Diergeneeskd 134:698-700 (in Dutch)

92. Hensinger T (2009) Trichomonas foetus. A pathogen responsible for diarrhoea in cats. Weterynaria w Praktyce 6:80-81

93. Lim S, Park SI, Ahn KS, Oh DS, Ryu JS, Shin SS (2010) First report of feline intestinal trichomoniasis caused by Tritrichomonas foetus in Korea. Korean J Parasitol 48:247-251

94. Miro G, Hernandez L, Montoya A, Arranz-Solis D, Dado D, Rojo-Montejo S, Mendoza-lbarra JA, Ortega-Mora LM, Pedraza-Diaz S (2011) First description of naturally acquired Tritrichomonas foetus infection in a Persian cattery in Spain. Parasitol Res 109:1151-1154

95. Forshell U, Osterman-Lind E (2010) Chronic diarrhoea caused by Tritrichomonas foetus in the cat. Svensk Veterinärtidning 62:19-21

96. Frey CF, Schild M, Hemphill A, Stunzi P, Muller N, Gottstein B, Burgener IA (2009) Intestinal Tritrichomonas foetus infection in cats in Switzerland detected by in vitro cultivation and PCR. Parasitol Res 104:783-788

97. Burgener IA, Frey CF, Kook PH, Gottstein B (2010) Tritrichomonas foetus: a new intestinal parasite in Swiss cats. Schweiz Arch Tierheilkd 151:383-389 (in German)

98. Gunn-Moore D, Tennant B (2007) Tritrichomonas foetus diarrhoea in cats. Vet Rec 160:850-851 